УДК 343.985 .5

12.00.00 Юридические науки

О КРИМИНАЛИСТИЧЕСКОЙ ХАРАКТЕРИСТИКЕ ПРЕСТУПЛЕНИЙ, СОВЕРШЕННЫХ ПРЕДСТАВИТЕЛЯМИ ОРГАНОВ МЕСТНОГО САМОУПРАВЛЕНИЯ

Данильян Сергей Александрович кандидат юридических наук, доцент кафедры криминалистики

Кубанский Государственный Аграрный

Университет, Краснодар, Россия

Данильян Элина Сергеевна

кандидат юридических наук

доцент кафедры криминалистики

Краснодарский Университет МВД России,

Краснодар, Россия

В статье рассмотрены элементы криминалистической характеристики преступлений, совершенных представителями органов местного самоуправления на основе изучения следственной практики. Выявлены способы совершения преступлений. Даны рекомендации и предложен перечень обстоятельств, характеризующих обстановку преступлений, совершенных представителями органов местного самоуправления

КЛючевые слова: КРИМИНАЛИСТИЧЕСКАЯ ХАРАКТЕРИСТИКА; СЛЕДОВАТЕЛЬ; ПРЕСТУПЛЕНИЕ; ЭЛЕМЕНТЫ; ОРГАН МЕСТНОГО САМОУПРАВЛЕНИЯ; РАССЛЕДОВАНИЕ; СЛЕДСТВЕННАЯ ПРАКТИКА; ОБСТОЯТЕЛЬСТВА; ДОКУМЕНТЫ
UDC 343.985.5

Legal sciences

\section{TO THE QUESTION OF CRIMINALISTIC CHARACTERISTICS OF CRIMES COMMITTED BY REPRESENTATIVES OF LOCAL SELF-GOVERNMENT BODIES}

Danilyan Sergey Alexandrovich

Cand.Leg.Sci., associate professor of the Criminalistics department

Kuban State Agrarian University, Krasnodar, Russia

Danilyan Elina Sergeievna

Cand.Leg.Sci., associate professor of the

Criminalistics department

Krasnodar University of the Ministry of Internal Affairs of Russia, Krasnodar, Russia

The article examines the elements of criminalistic characteristics of crimes committed by representatives of local self-government bodies on the basis of investigative practice studies. The methods of committing crimes have been revealed. There are some recommendations and a list of circumstances related to the situation of crimes committed by representatives of local self-government bodies

Keywords: CRIMINALISTIC CHARACTERISTICS; INVESTIGATOR; CRIME; ELEMENTS; LOCAL SELF-GOVERNMENT BODY; INVESTIGATION; INVESTIGATIVE PRACTICE; CIRCUMSTANCES; DOCUMENTS

Doi: 10.21515/1990-4665-130-091

$\begin{array}{cccc}\text { Знание } & \text { следователем } & \text { криминалистической } & \text { характеристики } \\ \text { преступлений, } & \text { совершенных } & \text { представителями органов } & \text { местного }\end{array}$ самоуправления, ведет к успеху его раскрытия и расследования. Криминалистическая характеристика преступления представляет собой научную категорию, в которой содержатся сведения о типичных признаках и свойствах события, обстановки, способа и механизма совершения общественно опасных деяний определенных видов и групп, процессах следообразования и типологических качествах личности и поведения виновных, потерпевших [1]. Среди ученых нет единого мнения о 
криминалистической характеристики преступления, и дискуссии продолжаются по настоящее время. Р.С. Белкин, первоначально отметивший важное значение криминалистической характеристики, впоследствии высказывал сомнения в еe необходимости и целесообразности существования и практического значения, так как при разработке ученые уклонялись от выявления корреляционных связей, а лишь регистрировали факты, в связи с чем эта научная категория из реальности превратилась в иллюзию, в криминалистический фантом [2].

Однако некоторые ученые считают, что криминалистическая характеристика - это неотъемлемый элемент методики расследования отдельных видов и групп преступлений. Практическое значение этой научной категории состоит в том, что она используется в качестве теоретической базы следственных версий и позволяет оптимизировать и существенно повышать эффективность расследования конкретных преступлений [3].

В криминалистической характеристике содержатся сведения, которые необходимы следователю для правильной организации расследования, выдвижения версий, выбора и применения тактических приемов. Это - первоначальная основа для эффективного и успешного расследования преступления.

К основным элементам структуры криминалистической характеристики преступлений, совершенных представителями органов местного самоуправления, относятся: способ совершения преступления и механизм следообразования; условия совершения преступления; характеристика виновного лица; характеристика потерпевшего лица.

Особенность обстановки преступлений данного вида обусловлена спецификой социальной сферы, в которой они совершаются, т. е. в области властных полномочий. 
В результате анализа следственной практики и литературы предложен перечень обстоятельств, характеризующих обстановку преступлений, совершенных представителями органов местного самоуправления: 1) Отрасль, профиль органа, учреждения, где находится на службе должностное лицо, структура органа и место в ней должностного лица. 2) Полномочия должностного лица. 3) Система документооборота, сопровождающего деятельность органа или учреждения, а также право принимать решения. 4) Система учета и контроля, пробелы в них, бесконтрольность на определенных участках службы. 5) Режим работы, процедура принятия решений. 6) Производственные, деловые, договорные и другие связи с другими органами и организациями; подчиненность и подконтрольность, личные и иные внеслужебные связи должностного лица. 7) Недостатки деятельности органа (бюрократизм, преступные традиции, недостатки в учете, отсутствие контроля). 8) Особенности законодательного регулирования деятельности должностного лица, в частности пробелы в нормативной регламентации, возможность принятия решения по усмотрению должностного лица, отсутствие отчетности и контроля, в том числе и морального в виде кодексов чести и поведения должностных лиц, и т. п.[4]

Деятельность органов местного самоуправления регулируется нормативно-правовыми актами, которые изданы на федеральном уровне, на уровне субъекта Федерации, местном уровне. Кроме них, существуют различные инструкции, постановления, которые регламентируют порядок выполнения определенных действий, входящих в компетенцию представителей органов местного самоуправления.

Полномочия должностных лиц и порядок их осуществления различаются в зависимости от административно-территориального уровня органа местной власти. Должностные лица муниципальных органов городов федерального значения обладают большими полномочиями по 
сравнению с должностными лицами администрации городов, находящихся под юрисдикцией субъектов Федерации. В свою очередь, полномочия республиканских, краевых, областных центров отличаются от полномочий и возможностей периферийных городов и регионов [5]. При изучении уголовных дел было установлено, что в каждом муниципальном образовании существует свой порядок выполнения определенных должностных и служебных действий.

Необходимо указать, что следователь при проведении предварительной проверки обязательно должен установить, в каком конкретно подразделении совершено противоправное действие, объем полномочий данного лица, порядок выполнения определенных действий и каким нормативно-правовым актом регулируется данная сфера. В связи с этим можно подразделить действия, осуществляемые: главой органа местного самоуправления; сотрудниками органа местного самоуправления, но визируемые главой; внутри отдела органа местного самоуправления; конкретным работником органа местного самоуправления; представителем органа местного самоуправления с привлечением других организаций, предприятий либо предпринимателей и физических лиц.

Местом совершения противоправных действий в большинстве случаев является служебное помещение. Однако при изучении уголовных дел было установлено, что представители органа местного самоуправления вознаграждение получают в различных общественных местах. При возникновении умысла на совершение противоправного действия представитель органа местного самоуправления продумывает место подготовки к преступлению. К таким местам относятся различные помещения, участки местности, где происходит сговор соучастников, введение в заблуждение потерпевшей стороны относительно выполнения определенных действий со стороны работников администрации, вымогательство у потерпевших денежных средств за 
совершение определенных действий работниками муниципального образования, подготовка различных фиктивных документов, разработка плана действий (в случае совершения преступления группой лиц по предварительному сговору).

Выполнение определенных действий, противоречащих интересам службы в муниципальном образовании и получение различного рода вознаграждений за совершение данных действий, изъятие бюджетных средств в свою пользу составляет основной этап способа совершения преступления. Действия, противоречащие интересам службы, совершаются представителями муниципального образования на рабочем месте, так как именно здесь происходит подписание различных документов, их составление, выдача различных приказов и распоряжений по различным вопросам и другие действия, входящие в компетенцию должностного лица органа местного самоуправления. Незаконное вознаграждение субъект преступления принимает как в рабочем кабинете, так и вне его, например, в парках, скверах, на остановках, на улице, в салоне автомобиля, в магазинах, торговых центрах, аэропортах и др. Данные места выбираются с учетом того, чтобы никто из людей, проходящих мимо не мог понять незаконный характер получения вознаграждения. Совершение противоправных действий в служебных помещениях объясняется тем, что именно здесь они чувствуют себя защищенными, уверенными, осознают общественную значимость, психологически устойчивы и т. п.

Групповые преступления, совершенные представителями органов местного самоуправления, латентны. Высокопоставленные чиновники не хотят огласки произошедшему и предпринимают все возможное для сокрытия своих действий либо бездействия в выявленном противоправном деянии.

Не менее важным элементом обстановки совершения преступления является время. Представители органов местного самоуправления 
выполняют противоправные действия в различные периоды времени. Однако субъекты преступления выбирают чаще всего рабочее время, так как именно в это время удобно совершить запланированное противоправное действие либо бездействие с использованием своих служебных полномочий.

Следующим элементом криминалистической характеристики преступлений, совершаемых представителями органов местного самоуправления, является способ совершения, который включает в себя систему действий по подготовке, совершению и сокрытию преступления, детерминированную условиями внешней среды и психофизическими качествами личности, связанными с избирательным использованием соответствующих средств и условий места и его времени [6].

И.А. Возгрин определил способ совершения преступления как систему взаимосвязанных и взаимообусловленных действий, включающих его подготовку, непосредственно совершение и сокрытие, с помощью которых преступник достигает своей цели [7]. Данная позиция обоснована и подтверждается следственной практикой.

Способы совершения преступлений, совершенных представителями органов местного самоуправления, зависят от отрасли их деятельности, профессионального опыта, образования, от занимаемой должности, от обстановки, от полномочий, наделенных трудовым договором, от практики, сложившейся в данном субъекте, регионе, от личности самого преступника.

К подготовительным действиям при совершении преступлений представителями органов местного самоуправления необходимо отнести разработку плана совершения противоправных действий, поиск соучастников, орудий, средств, необходимых для совершения данных действий, выбор удобного места и благоприятного времени для достижения преступной цели. 
Составление и подписание различных документов, а в некоторых случаях их согласование либо утверждение в различных подразделениях требуют от виновного лица проведения ряда подготовительных действий. К данным действиям можно отнести подготовку бланков (если бланки строгой отчетности, то их изготовление с помощью оргтехники), фальсификацию и оформление документов, подписание их в установленном порядке уполномоченным лицом либо проставление подложной подписи от данного лица. В ходе изучения следственной практики установлено, что в $35 \%$ случаев уполномоченные лица подписывают документы «не читая», а в остальных случаях происходит склонение, введение в заблуждение уполномоченных лиц с целью достижения принятия противоправного решения, а нередко данные лица вступают между собой в преступный сговор и совершают аналогичные преступления. Так, например, гр. К., являясь заведующей общим отделом администрации в 2008 г. в своем рабочем кабинете, имея доступ к официальным документам и печати поселения, изготовила и собственноручно заверила подложное свидетельство о праве собственности от 03.11.1992 г., в котором указано, что земельный участок площадью 1200 кв. м принадлежит ей, и, собрав весь необходимый пакет документов, предоставила в отдел Управления Федеральной регистрационной службы для регистрации права собственности на данный участок [8].

В органах муниципального самоуправления при оформлении документов сложилась установленная практикой и нормативными актами процедура оформления различных документов, которая связана с составлением, изучением, проверкой и подписанием их. Данный механизм подталкивает виновного к подысканию соучастников среди лиц, занимающихся составлением документов, проверкой, подписанием, а это, в свою очередь, относится к подготовительным действиям совершения 
преступления. В тех случаях, когда должностное лицо уполномочено визировать определенные документы, оно не прибегает к помощи посторонних лиц и не подыскивает соучастников, а самостоятельно выполняет все действия, необходимые для совершения преступления. Например, гр. Я., являясь заместителем главы администрации сельского округа, в обязанности которого не входит выделение земельных участков гражданам, заведомо зная о незаконности выделения себе земельного участка, решил завладеть земельным участком. Используя свое служебное положение, он изготовил и собственноручно подписал за главу администрации подложное постановление главы администрации «О закреплении бесплатно земельного участка в собственность для ведения личного подсобного хозяйства, за гр. Я.». После этого, путем обмана, убедил специалиста первой категории администрации сельского поселения гр. Б. в том, что указанное постановление законно, и, злоупотребив ее доверием, получил от последней необходимые для оформления межевых землеустроительных документов справки. Затем сдал изготовленное им фиктивное постановление и другие документы в Управление Федеральной регистрационной службы и получил свидетельство о праве собственности на данный участок [9].

В практике известны случаи, когда руководители пытаются скрыть свое участие в совершении противоправных действий, для этого они среди своих подчиненных или среди работников из другого отдела заинтересовывают в выполнении определенных противоправных действий за незаконное вознаграждение. К соучастникам относятся: руководители служб, отделов, помощники главы администрации, советники, заведующий сектором административно-хозяйственной части администрации, заведующий пресс-службой и др. Руководитель - организатор совершения преступления - возлагает всю ответственность на своих соучастников, а в ходе следствия дает показания о том, что не осведомлен о преступных 
действиях данных лиц. Например, глава администрации одного из поселений Краснодарского края гр. Б. вступил в сговор с гр. П., работающим в администрации муниципального образования, и совместно в 2008 г. они изготовили фиктивные постановления главы сельского округа о закреплении земельных участков в собственность за различными лицами [10].

Работники органов местного самоуправления совершают хищения денежных средств из бюджета района, города, края либо какого-либо имущества, стоящего на балансе. При совершении подобных преступлений необходимо учитывать полномочия субъекта по распоряжению данным имуществом либо денежными средствами. Согласно действующему законодательству любое движение товарно-материальных ценностей должно быть отражено в документах бухгалтерской отчетности. Поэтому при совершении противоправных действий, касающихся движения бюджетных денежных средств либо имущества, стоящего на балансе органа местной власти, соучастниками преступления являются бухгалтерские работники данного муниципалитета, т.к. без их участия невозможно провести необходимые операции и незаконно получить денежные средства в кассе муниципального органа и в подчиненных ему подразделениях.

Примером могут служить материалы уголовного дела в отношении гр. С., работающего заведующим сектором административнохозяйственной части муниципального органа, который на протяжении нескольких месяцев в 2008 г. по предварительному сговору с ведущим специалистом отдела бухгалтерского учета и отчетности из личной заинтересованности внес в официальные документы бухгалтерской отчетности заведомо ложные сведения, искажающие их действительное содержание, и получил из кассы денежные средства [11]. 
Непосредственное совершение преступлений представителями органов местного самоуправления включает в себя следующие действия: выполнение служебных, должностных обязанностей и получение незаконного вознаграждения или противоправное приобретение права на имущество, ценности, которое принадлежит иным лицам либо государству.

Незаконное вознаграждение может быть получено должностным лицом за совершение законных действий, входящих в его должностные обязанности. Например, гр. К., занимая должность главного специалиста отдела градостроительного контроля, являясь должностным лицом, выполняя административно-хозяйственные функции в органе местного самоуправления, 18 июня 2010 г. в дневное время, находясь в своем рабочем кабинете, умышленно, из корыстных побуждений, получил взятку в виде денег в сумме 20000 рублей за действия в пользу гр. Ш., а именно за выдачу разрешения на установку наружной рекламной конструкции [12].

К традиционным действиям, совершаемым представителями органов местного самоуправления, относятся изготовление и использование подложных (фиктивных) документов. В результате изучения следственной практики установлено, что представители органа местного самоуправления принимают решения, утверждая различные документы, при этом они осведомлены в том, что документы подложные. Сами представители власти могут участвовать в изготовлении либо лично их изготавливать, приобретении различных документов, в которых содержатся фиктивные сведения. Участие данных лиц заключается в оказании содействия в получении документов, они непосредственно их выдают, вносят изменения в другие документы, которые содержат достоверные сведения, и т. д. В следственной практике Краснодарского края известен случай, когда гр. Б., занимающая должность специалиста 
администрации сельского поселения, используя свое служебное положение, изготовила несколько десятков дубликатов фиктивных постановлений главы сельского округа о закреплении разных земельных участков за гражданами, внесла изменения в похозяйственную книгу, тем самым совершила серию мошенничеств [13].

При анализе преступлений, совершаемых представителями органов местного самоуправления, установлено, что данные лица после выполнения определенных действий получали незаконное вознаграждение: в 93\% случаев им передавались денежные средства, а в остальных 7\% случаев другое вознаграждение (передача права собственности на земельный участок, перерегистрация права собственности на автомобиль, оказание различных услуг). Выявлено также, что некоторые руководители отделов местного самоуправления или структурных подразделений совершают хищения путем начисления и получают различные разовые выплаты, либо премии, надбавки за невыполненные работы, либо начисляют заработанную плату лицу, которое фактически не выходит на работу и не выполняет обязанности по занимаемой должности, и т. д. Например, гр. Б., являясь директором муниципального учреждения, 31 июля 2009 г., находясь в своем рабочем кабинете, из корыстной заинтересованности, достоверно зная о том, что имеется вакантная должность культорганизатора, собственноручно в письменной форме составила ложное заявление от имени своей сестры, о приеме ее на работу на данную должность и поставила от своего имени соответствующую резолюцию. После составила ложный официальный документ - приказ о приеме сестры на работу, внесла в штатное расписание заведомо ложные и не соответствующие действительности сведения, на данном приказе гр. Б. поставила свою подпись. После начисления заработанной платы снимала ее с пластиковой карты Сбербанка РФ и распоряжалась ими по своему усмотрению [14]. 
Хищения с использованием должностного и служебного положения работниками предприятий и организаций при органах местной власти также совершаются в форме присвоения и растраты. Способы этих хищений довольно многообразны и зависят от сферы деятельности предприятия. В наиболее общем виде способы присвоения и растраты можно разделить на совершаемые с применением мер по сокрытию содеянного или без такового. Кроме того, они классифицируются по созданию источника, резервов ценностей для последующего расхищения: создание пересортицы, завышение объемов и стоимости выполненных работ; прием ценностей без оформления приходных документов; составление бестоварных документов на расходование денежных средств и имущества; присвоение денежных средств под предлогом возврата клиентам или фальсификации записей в платежных документах и т. п. [15]

При изучении следственной практики установлено, что в $35 \%$ изученных дел применялось сокрытие преступления, представляющее собой умышленные действия, заключающиеся в утаивании, маскировке, фальсификации, уничтожении доказательственной информации и ее носителей с целью уклонения виновного от уголовной ответственности. Сокрытие субъектами противоправной деятельности реализовывалось на всех стадиях осуществления преступного замысла. Сокрытие по рассматриваемой категории преступлений заключается в использовании условий обстановки, утаивании от окружающих характера планируемых и совершаемых преступлений. В этих же целях используются документы, содержащие фиктивные сведения, сообщения умышленно ложных сведений с целью совершения определенных служебных действий, утаивания либо уничтожения какой-либо информации о совершенных служебных действиях противоправного характера.

При раскрытии и расследовании преступлений, совершаемых представителями органов местного самоуправления следователь, 
оперативный работник сталкиваются с определенными трудностями, так как в большинстве случаев данные противоправные действия совершаются без свидетелей, происходит маскировка следов. Однако, как бы преступники не старались, следы все равно остаются. Следы по данной категории преступлений бывают как идеальные, так и материальные. Материальными следами по данной категории преступлений являются предметы преступления, их упаковка, ярлыки, почтовые переводы, вклады в банках, фото- и видеоматериалы, которые свидетельствуют о контакте субъектов преступной деятельности или о самом совершении преступления, различные документы, в которых отражены действия данных субъектов противоправной деятельности, следы рук, следы химических веществ на руках и т. п.

Анализ следственной практики показал, что представители органов местного самоуправления, совершая противоправные действия, скрывая их, оставляют следы в подлинных и сфальсифицированных документах.

В криминалистической литературе неоднократно было отмечено мнение ученых о том, что преступник и потерпевший - два взаимодействующих субъекта совершения преступления. Они порождают криминалистически значимые взаимообусловленные связи, отражающиеся в объектах материальной обстановки места совершения преступления [16].

Расследование по уголовному делу на должном уровне невозможно без изучения следователем, работником дознания личности потерпевшего. Обоснованность возбуждения уголовного дела, правильное принятие многих процессуальных решений, правильная квалификация противоправных действий, выдвижение и проверка версий, установление мотива совершения преступления, причин и условий, способствовавших совершению преступления, зависят от объема полученной информации о личности потерпевшего. 
Потерпевшим по данной категории преступлений может быть как физическое лицо, так и органы государственной власти, другие организации.

Выявление и изучение криминалистически значимых особенностей личности потерпевшего и их поведение дают возможность глубже разобраться во многих обстоятельствах преступления, особенно указывающих на своеобразие, направленность и мотивы поведения преступника, его общие (типовые) и индивидуальные свойства.

\section{Литература}

1. Драпкин Л.Я. Предмет доказывания и криминалистические характеристики преступлений // Криминалистические характеристики в методике расследования преступлений. Свердловск, 1978. С. 17.

2. Белкин Р.С. Криминалистика: проблемы сегодняшнего дня. Злободневные вопросы российской криминалистики. М.: НОРМА, 2001. С. 223.

3. Герасимов И.Ф. и др. Криминалистические характеристики преступлений в структуре частных методик // Криминалистические характеристики в методике расследования преступлений. Свердловск, 1978. С. 5-10.

4. Баженов А.И. Досудебное производство по делам о преступлениях против государственной власти, интересов государственной службы и службы в органах местного самоуправления: дис. ... канд. юрид. наук. Калининград, 2009. С. 65.

5. Башмаков И.С. Особенности первоначального этапа расследования коррупционных преступлений, совершаемых представителями органов местной власти. М.: Юрлитинформ, 2007. С. 42.

6. Зуйков Г.Г. Криминалистическое учение о способе совершения преступления: дис. ... д-ра юрид. наук. М.: Академия МВД СССР, 1970. С. 305.

7. Криминалистика: учеб. / под ред. Т.А. Седовой, А.А. Эскархопуло. СПб.: Изд-во Санкт-Петерб. ун-та, 1995. С. 358.

8. Архив Динского районного суда Краснодарского края. Уголовное дело №218349/2011.

9. Архив Динского районного суда Краснодарского края. Уголовное дело №118575/2010.

10. Архив Динского районного суда. Уголовное дело № 118483/20010.

11. Архив Следственного отдела ОМВД России по Северскому району. Уголовное дело № 879931/2008.

12. Архив Кореновского районного суда. Уголовное дело № 783721/2010.

13. Архив Динского районного суда. Уголовное дело № 918965/2009.

14. Архив Тихорецкого районного суда. Уголовное дело № 179068/2010.

15. Гаврилина 3.Т. Характеристика способов хищений: понятие, классификация и значение для расследования // Руководство для следователя, 2-е изд., перераб. / под ред. П.А. Алейника, О.В. Сороки. - М., 1982. С. 4-5.

16. Густов Г.А. Расследование должностных хищений в торговле // Криминалистическая характеристика преступлений. Л., 1991. С. 46. 
17. Евдокимов С.Г. Криминалистическая характеристика присвоения и растраты // Курс криминалистики: в 3 т. Т. 3. Криминалистическая методика: методика расследования преступлений в сфере экономики, взяточничества и компьютерных технологий. СПб., 2004. С. 86-87.

18. Баженов А.И. Досудебное производство по делам о преступлениях против государственной власти, интересов государственной службы и службы в органах местного самоуправления: дис. ... канд. юрид. наук. Калининград, 2009. С. 63-64.

\section{References}

1.Drapkin L.Ja. Predmet dokazyvanija i kriminalisticheskie harakteristiki prestuplenij // Kriminalisticheskie harakteristiki v metodike rassledovanija prestuplenij. Sverdlovsk, 1978. S. 17.

2.Belkin R.S. Kriminalistika: problemy segodnjashnego dnja. Zlobodnevnye voprosy rossijskoj kriminalistiki. M.: NORMA, 2001. S. 223.

3.Gerasimov I.F. i dr. Kriminalisticheskie harakteristiki prestuplenij v strukture chastnyh metodik // Kriminalisticheskie harakteristiki v metodike rassledovanija prestuplenij. Sverdlovsk, 1978. S. 5-10.

4.Bazhenov A.I. Dosudebnoe proizvodstvo po delam o prestuplenijah protiv gosudarstvennoj vlasti, interesov gosudarstvennoj sluzhby i sluzhby $\mathrm{v}$ organah mestnogo samoupravlenija: dis. ... kand. jurid. nauk. Kaliningrad, 2009. S. 65.

5.Bashmakov I.S. Osobennosti pervonachal'nogo jetapa rassledovanija korrupcionnyh prestuplenij, sovershaemyh predstaviteljami organov mestnoj vlasti. M.: Jurlitinform, 2007. S. 42.

6.Zujkov G.G. Kriminalisticheskoe uchenie o sposobe sovershenija prestuplenija: dis. ... d-ra jurid. nauk. M.: Akademija MVD SSSR, 1970. S. 305.

7.Kriminalistika: ucheb. / pod red. T.A. Sedovoj, A.A. Jeskarhopulo. SPb.: Izd-vo Sankt-Peterb. un-ta, 1995. S. 358.

8.Arhiv Dinskogo rajonnogo suda Krasnodarskogo kraja. Ugolovnoe delo №218349/2011.

9.Arhiv Dinskogo rajonnogo suda Krasnodarskogo kraja. Ugolovnoe delo №118575/2010.

10.Arhiv Dinskogo rajonnogo suda. Ugolovnoe delo № 118483/20010.

11.Arhiv Sledstvennogo otdela OMVD Rossii po Severskomu rajonu. Ugolovnoe delo № 879931/2008.

12.Arhiv Korenovskogo rajonnogo suda. Ugolovnoe delo № 783721/2010.

13.Arhiv Dinskogo rajonnogo suda. Ugolovnoe delo № 918965/2009.

14.Arhiv Tihoreckogo rajonnogo suda. Ugolovnoe delo № 179068/2010.

15.Gavrilina Z.T. Harakteristika sposobov hishhenij: ponjatie, klassifikacija i znachenie dlja rassledovanija // Rukovodstvo dlja sledovatelja, 2-e izd., pererab. / pod red. P.A. Alejnika, O.V. Soroki. - M., 1982. S. 4-5.

16.Gustov G.A. Rassledovanie dolzhnostnyh hishhenij v torgovle // Kriminalisticheskaja harakteristika prestuplenij. L., 1991. S. 46.

17.Evdokimov S.G. Kriminalisticheskaja harakteristika prisvoenija i rastraty // Kurs kriminalistiki: v 3 t. T. 3. Kriminalisticheskaja metodika: metodika rassledovanija prestuplenij v sfere jekonomiki, vzjatochnichestva i komp'juternyh tehnologij. SPb., 2004. S. 86-87.

18.Bazhenov A.I. Dosudebnoe proizvodstvo po delam o prestuplenijah protiv gosudarstvennoj vlasti, interesov gosudarstvennoj sluzhby i sluzhby v organah mestnogo samoupravlenija: dis. ... kand. jurid. nauk. Kaliningrad, 2009. S. 63-64. 